\title{
DOENÇA EPITELIOCÍSTICA EM Tilapia nilotica (Linnaeus, 1758) NO ESTADO DO RIO DE JANEIRO, BRASIL
}

\author{
EPITHELIOCYSTIS DISEASE IN Tilapia nilotica (Linnaeus, 1758) FROM \\ RIO DE JANEIRO STATE, BRAZIL
}

\author{
Francisco Carlos de Lima ${ }^{1}$ Alexandre Paes Goulart Machado ${ }^{2}$ Aline Pinheiro Borges ${ }^{2}$ \\ Carlos Henrique Azeredo Lima ${ }^{2}$ Cláudio de Moraes Andrade \\ Eliana de Fátima Marques de Mesquita ${ }^{1}$
}

\section{- NOTA .}

RESUMO

Cistos branquiais são descritos em oito exemplares de Tilapia nilotica, no Estado do Rio de Janeiro. Os cistos epiteliais consistiam de hipertrofia das células do epitélio branquial que mostravam um único e grande corpúsculo de inclusão basofílico. A enfermidade relatada apresenta as características peculiares da doença epiteliocística.

Palavras-chave: doença epiteliocística, Tilapia nilotica.

SUMMARY

Branchial cysts are described in eight specimens of Tilapia nilotica from the state of Rio de Janeiro, Brazil. Cysts consisted of hypertrophy of branchial epithelial cells, which dysplayed a single basophilic corpuscle. The disease reported has the microscopic hallmarks of epitheliocystis.

Key words: epitheliocystis disease, Tilapia nilotica.

A doença epiteliocística é um processo infeccioso que pode afetar uma grande variedade de espécies de peixes em todo o mundo. É causada por um grande número de organismos dos grupos Rickettsia e Chlamydia (WOLKE et al., 1970;
ZACHARY \& PAPERNA, 1977; NYLUND et $\boldsymbol{a l}$., 1998). A doença foi descrita, pela primeira vez, por HOFFMAN et al. (1969), em Lepomis macrochirus Raffinesque, nos Estados Unidos. Descrita como uma enfermidade crônica, mostra, como característica histopatológica distinta, a presença de células epiteliais hipertróficas da pele e das brânquias, preenchidas com material granular basofílico. Na América do Sul, CARVAJAL et al. (1990) registraram a doença em Oncorhynchus kisutch Walbaum e Salmo salar Linnaeus, no Chile, e VENIZELOS \& BENETTI (1996) em Seriola mazatlana, no Equador. O objetivo deste trabalho foi registrar a presença da doença epiteliocística em Tilapia nilotica no Brasil.

No presente estudo, trinta espécimes juvenis de $\boldsymbol{T}$. nilotica, que serviriam inicialmente para estudos histológicos, foram coletados dos lagos da Estação de Piscicultura da Universidade Federal Rural do Rio de Janeiro (UFRRJ). O comprimento padrão dos animais variou de quatro a sete centímetros. Após a mensuração dos exemplares, foi efetuada uma incisão na parede ventral da cavidade geral,

\footnotetext{
${ }^{1}$ Médico veterinário, Professores Adjunto IV, Departamento de Tecnologia de Alimentos, Faculdade de Veterinária, Universidade Federal Fluminense, Rua Vital Brazil Filho, 64, Niterói, RJ. 24230-340. Autor para correspondência: Professora Eliana de Fátima M. Mesquita -E-mail: eliana@esquadro.com.br.

${ }^{2}$ Médicos Veterinários.

${ }^{3}$ Laboratório de Virologia Veterinária, UFRRJ, Brasil. 
do ânus até a altura dos opérculos. Os peixes eram, em seguida, imersos em solução de formol a $10 \%$ por 48 horas. Fragmentos dos vários tecidos foram colhidos, desidratados em álcool absoluto e clarificados em xilol, embebidos em parafina, cortados com cinco micrômetros de espessura e corados pela hematoxilina-eosina.

Não foram observadas lesões macroscópicas, porém, a análise microscópica dos cortes de brânquias de oito peixes evidenciou lesões císticas peculiares que variavam entre 20,8 x 15,6 e 59,8 x $36,4 \mu \mathrm{m}$. Os cistos eram caracterizadas por hipertrofia das células epiteliais das lamelas secundárias que continham um único e volumoso corpúsculo de inclusão, que ocupava todo o interior da célula, constituído de finos grânulos basofílicos (Figura 1), como as lesões reportadas por HOFFMAN et $\boldsymbol{a l}$. (1969), WOLKE et al. (1970), ZACHARY \& PAPERNA (1977) e VENIZELOS \& BENETTI (1996). Foi notada, também, uma camada de células epiteliais cuboidais cobrindo as células epiteliocísticas como descrito por ZACHARY \& PAPERNA (1977) em Morone saxatilis Walbaum. Pelas lesões descritas em $\boldsymbol{T}$. nilotica pode-se firmar o diagnóstico de doença epiteliocística.

Outra doença, de natureza e características distintas, denominada lymphocystis ou doença linfocística, deve ser diferenciada da doença epiteliocística. No entanto, vários aspectos permitem fazer um diagnóstico diferencial seguro. Segundo ROBERTS (1978), a doença linfocística não é freqüente em brânquias, sendo mais comum o acometimento da pele; a célula infectada é o fibroblasto; os cistos apresentam cápsula hialina e os núcleos são aumentados, porém em posição não periférica e, nos estágios avançados da doença, exibem diferentes graus de lise; apresentam um ou mais nucléolos e o

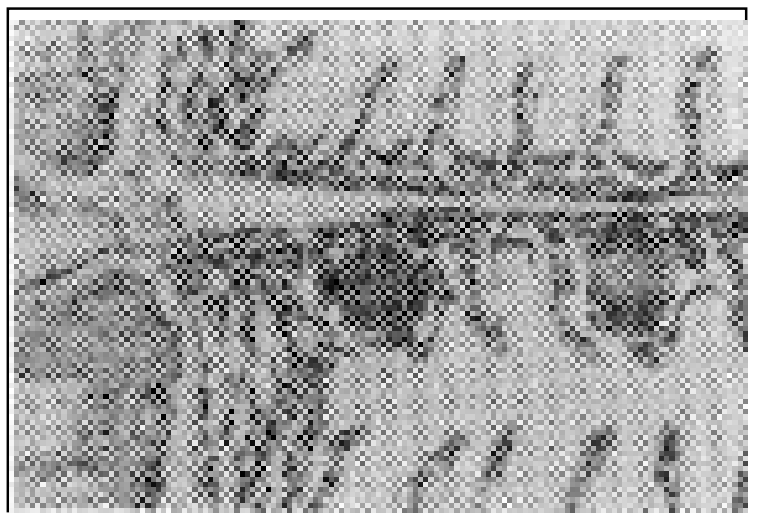

Figura 1 - Fotomicrografia de brânquias de Tilapia nilotica mostrando duas grandes células epiteliocísticas em uma lamela secundária (setas). Notam-se as enormes inclusões granulares basofilicas. O núcleo aparece deslocado para a periferia da célula.(H\&E - 400X). citoplasma é granular com uma ou mais inclusões basofílicas; as células linfocísticas mostram reação inflamatória do tipo epitelióide, além de elementos linfóides. As dimensões dos cistos da doença linfocística são muito maiores que as da doença epiteliocística (HOFFMAN et al., 1969).

Embora a doença epiteliocística apresente, na maioria das vezes, baixa prevalência (ANDERSON \& PRIOR, 1992) e alterações histológicas de pouca importância (KENT et al., 1998), pode também mostrar prevalência alta (NOWAK, 1996) e ser responsável por infecções graves e alta mortalidade (VENIZELOS \& BENETTI, 1996; NYLUND et al., 1998). Os cortes histológicos de tecidos de juvenis de $\boldsymbol{T}$. nilotica examinados mostraram pouca quantidade de cistos epiteliais branquiais, já que o número de cistos por animal variou de um a três, insuficientes para promover patologia aparente.

\section{REFERÊNCIAS BILBIOGRÁFICAS}

ANDERSON, I.G., PRIOR, H.C. Subclinical epitheliocystis in barramundi, Lates calcarifer, reared in sea cages. Australian Veterinary Association, v.69, p.226-227, 1992.

CARVAJAL, J., RUIZ, G., GONZALES, L. Histopatologias branquiales presentes en salmones coho (Oncorhynchus kisutch) y atlantico (Salmo salar) en condiciones de cultivo en el sur de Chile. Ambientes Acuaticos, v.11, p.53-58, 1990 .

HOFFMAN, G.L., DUNBAR, C.E., WOLF, K., et al. Epitheliocystis, a new infectious disease of the bluegill (Lepomis macrochirus) Antonie van Leeuwenhoek, v.35, p.146-158, 1969.

KENT, M.L., TRAXLER, G.S., KIESER, D., et al. Survey of salmonid pathogens in ocean-caught fishes in British Columbia, Canada. Journal of Aquatic Animal Health, v.10, p. 211-219, 1998.

NOWAK, B.F. Health of red morwong, Cheilodactylus fuscus, and rock cale, Crinodus lophodon, from Sydney cliff-face sewage outfalls. Marine Pollution Bulletin, v.33, n.7/12, p.281-292, 1996 .

NYLUND, A., KVENSETH, A.M., ISDAL, E. A morphological study of the epitheliocystis agent in farmed Atlantic salmon. Journal of Aquatic Animal Health, v.10, p.43-55, 1998.

ROBERTS, R.J. Fish pathology. London : Baillière Tindall, 1978. $318 \mathrm{p}$.

WOLKE, R.E., WYAND, D.S., KHAIRALLAH, L.H. A light and electron microscopic study of epitheliocystis disease in the gills of Connecticut striped bass (Morone saxatilis) and white perch (Morone americanus). Journal of Comparative Pathology, v.80, p.559-563, 1970.

VENIZELOS, A., BENETTI, D.D. Epitheliocystis disease in cultured yellowtail Seriola mazatlana in Ecuador. Journal of the World Aquaculture Society, v.27, n.2, p.223-227, 1996.

ZACHARY, A., PAPERNA, I. Epitheliocystis disease in the striped bass Morone saxatilis from the Chesapeake Bay. Canadian Journal of Microbiology, v.23, p.1404-1414, 1977. 